Reports

\title{
When do primes prime? The moderating role of the self-concept in individuals' susceptibility to priming effects on social behavior
}

\author{
Dirk Smeesters ${ }^{\mathrm{a}, *}$, Vincent Y. Yzerbyt ${ }^{\mathrm{b}}$, Olivier Corneille ${ }^{\mathrm{b}}$, Luk Warlop ${ }^{\mathrm{c}}$ \\ ${ }^{a}$ Rotterdam School of Management, Erasmus University, P.O. Box 1738, 3000 DR Rotterdam, The Netherlands \\ ${ }^{\mathrm{b}}$ Université catholique de Louvain, Louvain-la-Neuve, Place du Cardinal Mercier 10, B-1348 Louvain-la-Neuve, Belgium \\ ${ }^{c}$ Katholieke Universiteit Leuven, Leuven, Naamsestraat 69, B-3000 Leuven, Belgium
}

\section{A R T I C L E I N F O}

Article history:

Received 3 August 2007

Revised 2 September 2008

Available online 12 September 2008

\section{Keywords:}

Priming

Automaticity

Self-concept

Self-activation

Social value orientation

Consistency

\begin{abstract}
A B S T R A C T
Using cooperative behavior in economic decision-making settings, we predicted and found that people's susceptibility to priming influences is moderated by two factors: people's chronic accessibility to a behavioral repertoire and people's self-concept activation. In Experiment 1, we show that individuals highly consistent in their social value orientation (SVO) assimilate their behavior to their dispositions rather than to the primes, whereas the opposite effect is obtained among individuals with a low consistent SVO. In Experiment 2, we show that low consistent SVO individuals become less susceptible to priming influences when their self-concept is activated. These studies shed new light on individuals' susceptibility to priming influences on social behavior.
\end{abstract}

(c) 2008 Elsevier Inc. All rights reserved.
Behaviors are often under the influence of situational cues. Oneway social cognition research has operationalized situational influences is by relying on priming techniques. Primes can increase the accessibility of prime-consistent behavioral responses that orient social behavior (for reviews, see Bargh \& Ferguson, 2000; Dijksterhuis, Chartrand, \& Aarts, 2007; Wheeler \& Petty, 2001). However, individuals are also characterized by dispositions that determine their behavior. The question then is under which conditions individuals are less susceptible to priming influences, such that their dispositions, rather than priming influences, determine their social behavior. The present paper studies the combined role of two factors attenuating behavioral priming effects.

A first factor is individuals' chronic accessibility to a class of behavioral responses, as determined by the strength of their selfconcept (Markus, 1977). Individuals with chronically accessible behavioral responses may be in general less susceptible to priming influences than are individuals for whom these behavioral responses are not or are less chronically accessible. A second factor is the activation of the self-concept (Carver \& Scheier, 1981). Individuals may be in general less susceptible to priming influences when the self-concept is highly activated than when it is not. In two studies, we examined these propositions in the context of cooperative behavior in economic decision-making settings. We tested the influence of cooperation and competition related primes

\footnotetext{
* Corresponding author.

E-mail address: dsmeesters@rsm.nl (D. Smeesters).
}

on behavior for individuals differing in their Social Value Orientation (SVO), which refers to a relatively stable behavioral tendency with respect to cooperation (McClintock, 1972). In Experiment 1, we tested whether chronic access to a behavioral repertoire, as determined by the strength of individuals' dispositions, can attenuate behavioral priming effects. Specifically, individuals with a high consistent SVO (i.e., who have a highly accessible chronic SVO) are less susceptible to priming influences than are individuals with a low consistent SVO (i.e., who have a less accessible chronic SVO). In Experiment 2, we demonstrated the important role of self-concept activation by showing that individuals with a less accessible chronic SVO can also become less susceptible to priming influences when their self-concept is activated.

\section{When do primes prime?}

It is well documented that exposure to trait and stereotype primes can affect social behavior. In a seminal paper by Bargh, Chen, and Burrows (1996), participants primed with rudeness interrupted a conversation faster than participants primed with politeness. In another experiment, participants exposed to elderly stereotype-related words walked down a hallway more slowly than did control participants. These effects have been widely replicated across many behavioral domains, such as helping behavior, cooperation behavior, and conforming/normative behavior (e.g., Aarts \& Dijksterhuis, 2003; Epley \& Gilovich, 1999; Hertel \& Fiedler, 1994; Kay \& Ross, 2003; Nelson \& Norton, 2005; Neuberg, 1988; Smeesters, Wheeler, \& Kay, in press; Utz, 2004; Utz, 
Ouwerkerk, \& Van Lange, 2004). However, individuals should not always be under the influence of primed constructs. Individuals also possess a self-concept (including traits, dispositions, attitudes) that can determine their behavioral responses. Individuals may differ in both the content and the strength of their self-concept (DeMarree, Petty, \& Brinol, 2007; Epstein, 1983). Which of these factors, primes or self-concept, determines social behavior may in fact depend on a number of boundary conditions, two of which are discussed and examined here.

\section{Chronic accessibility of the self-concept}

Individuals with strong dispositions tend to possess highly accessible chronic self-concept content, which means that they tend to enact consistently the behavioral responses that are part of their self-concept (Wheeler, DeMarree, \& Petty, 2007). This chronically active self-concept content likely makes individuals less susceptible to primes. In contrast, individuals with weaker dispositions possess less accessible chronic self-concept content. This means that they are less likely to consistently enact the behavioral responses as determined by their self-concept (Wheeler et al., 2007) and, instead, should be more susceptible to priming concepts. In sum, we argue that the behavior of individuals with a highly accessible self-concept is determined by their self-concept whereas the behavior of individuals with a less accessible self-concept is determined by priming influences. We tested this hypothesis in Experiment 1.

\section{Self-concept activation}

When behavioral responses are not chronically accessible, for instance because individuals have a weak disposition, situational primes may take precedence over such 'weak' internal tendencies. This should however not mean that individuals with less accessible self-concept content should always be susceptible to priming influences. Research suggested that individuals are less susceptible to situational cues when the self is made salient (Carver \& Scheier, 1981; Dijksterhuis \& Van Knippenberg, 2000). Hence, activating the self-concept may render action-relevant chronic self-concept more accessible, thereby increasing the likelihood that behavioral tendencies rather than primes orient behavior. Hence, individuals with less accessible self-concept content may be more resistant to priming influences when their self is activated in the situation compared to when the self is not activated. This hypothesis was tested in Experiment 2.

\section{The present research}

In two experiments, we gathered evidence for the role of the two proposed factors. We primed participants with religious, business, and neutral words, and examined the effects on decisions in economic decision-making situations. Religious and business concepts have been found to be associated with cooperation and competition, respectively (De Dreu, Yzerbyt, \& Leyens, 1995). In addition to primes, we examined the influence of a disposition, part of individuals' self-concept, that is known as Social Value Orientation (SVO). We also took into account the consistency of $S V O$, which reflects differences in the self-concept strength of SVO (Hertel \& Fiedler, 1998).

SVO is a relatively stable preference for specific patterns of outcomes for oneself and others (McClintock, 1972). The extant research supports a three-category typology of orientations, characterizing different types of individuals (Messick \& McClintock, 1968; Van Lange, 1999): pro-socials tend to enact behaviors that maximize joint outcomes along with equality; individualists tend to maximize own outcomes; and competitors tend to maximize the relative advantage over other's outcomes. Individualists and competitors both have a primary concern for own outcomes, absolutely or relatively, and are therefore considered as one group of pro-selfs (Sattler \& Kerr, 1991; Van Lange \& Liebrand, 1989). Past research revealed that relative to pro-selfs, pro-socials exhibit greater cooperation toward others and are more likely to exhibit reciprocity and concern with fairness in outcome distributions (Smeesters, Warlop, Van Avermaet, Corneille, \& Yzerbyt, 2003; Van Lange, 1999).

Next to differences in the (pro-social and pro-self) nature of SVO, there also tend to be differences in the consistency of individuals' SVO. The consistency variable refers to the regularity in the choice pattern with which an individual's type of SVO is measured. The Ring Measure of Social Values (Liebrand, 1984) has been developed to measure an individual's SVO. This technique consists of several choice trials, each presenting different combinations of outcomes for the self vs. another person. Individuals must indicate on each trial which combination they prefer the most. Adding up all the preferred amounts of outcomes for the self and the other indicates an individual's dominant (pro-social vs. pro-self) SVO. A maximal consistency score implies that an individual chooses all self/other outcome combinations consistent with his/her dominant SVO, but the score decreases when individuals choose according to another SVO on some trials. Differences in consistency reveal differences in the self-concept strength of SVO or differences in the extent to which individuals are motivated to enact their most dominant behavioral tendency (Hertel \& Fiedler, 1998).

Participants with a high consistent SVO tend to enact consistently their dominant (either pro-social or pro-self) behavioral tendencies and can be considered as "schematic" pro-socials or proselfs. Hence, they possess a highly accessible chronic pro-social or pro-self self-concept (Wheeler et al., 2007), which likely makes them in general more resistant to relevant primes. In contrast, participants with a low consistent SVO are less intended to consistently enact their dominant behavioral pro-social or pro-self tendencies. They possess less accessible chronic self-concept content (Wheeler et al., 2007) and, hence, should be more susceptible to relevant priming concepts. Following our theorizing, we expect high consistent SVO individuals to be less susceptible to priming influences than low consistent SVO individuals.

Experiment 1 examined the moderating role of chronic accessibility of the self-concept on the impact of primed constructs on behavior. In Experiment 2, we examined low consistent SVO individuals' susceptibility to priming influences as a function of selfactivation.

\section{Experiment 1}

Participants played a dictator game (Bohnet \& Frey, 1999). They allocated outcomes between themselves and another person who had no money to allocate and no power in terms of either accepting or rejecting the "dictator's" offer. Participants' SVO and consistency of SVO were measured with the Ring Measure. After a long filler task, participants were randomly assigned to three priming conditions: neutral, religious, and business primes.

Based on our hypothesis that individuals with highly accessible self-concept content should be less susceptible to priming influences than individuals with less accessible self-concept content, we expected that only SVO would affect cooperative behavior of high consistent SVO individuals whereas only primes would affect the behavior of low consistent SVO individuals. More specifically, for high consistent SVO individuals, those with a pro-social orientation should allocate more to the other than those with a pro-self orientation. For low consistent SVO individuals, priming influences 
should override SVO influences, such that they should allocate more (fewer) outcomes to the other in the religious (business) priming condition compared to the control priming condition.

\section{Method}

\section{Participants}

Participants were 169 undergraduates who participated in partial fulfillment of course requirements. Participants completed the Ring Measure of Social Values (Liebrand, 1984) which measures their SVO and the consistency of their SVO, and were then randomly assigned to one of three priming conditions (religious vs. neutral vs. business).

\section{Procedure and materials}

Participants were told that they would be performing several unrelated tasks, which they performed in individual cubicles.

Measuring SVO and consistency of SVO. Participants first performed the Ring Measure of Social Values (Liebrand, 1984), a computerized task that consists of 24 choice trials. On each trial two different combinations of amounts of money for the self and an imaginary other are presented. Combinations are sampled from points on a circle in a two-dimensional outcome space, defined by a horizontal dimension representing the own outcomes and a vertical dimension representing the other's outcomes. The center of the circle coincides with the origin of the outcome plane $\left(\mathrm{BEF}^{1} 0\right.$ for the self and for the other). The radius of the circle is BEF 1500. Each choice trial consists of two equidistant own/other outcome combinations that are located next to each other on the circle. An example of a pair is the choice between Alternative A: BEF 750 for the self and BEF -1300 for the other and Alternative B: BEF 390 for the self and BEF -1450 for the other. Because every outcome combination has two equidistant adjacent combinations, each combination is presented on two choice trials. This results in 24 different choice trials of adjacent outcome combinations. On each trial, participants had to choose the alternative they most preferred. Adding up the chosen amounts separately for self and for the other provides two totals that can be represented as coordinates on the horizontal axis and the vertical axis, defining a single point in the plane. This point provides the direction of the participant's SVO vector in the outcome plane. An individual's SVO is usually indicated by the angle the SVO vector makes with the horizontal, own outcomes, axis. Each SVO reflects a unique pattern of choices. On each trial, an individual can make a decision that is consistent or inconsistent with his/her preferred direction of SVO. A consistent choice means choosing-in a pair of adjacent outcome combinations-the combination that is closest to the preferred direction of SVO. Maximal consistency occurs when an individual's choices are consistent with his/her preferred SVO (Liebrand, 1984). The consistency score decreases each time an individual chooses according to another SVO on some trials.

Priming manipulation. After participants finished a filler task, they were presented with a word-recognition task. Participants sat in front of a computer screen, and were told that they would be presented with 30 letter strings appearing one by one on the screen. Half of these letter strings were existing words, the other half were non-existing words. Each trial started with the presentation of a fixation point on the screen. Participants had to press the key '2' to start a trial. They had to decide as quickly as possible whether or not a string was an existing word by pressing a key on the key-

\footnotetext{
${ }^{1}$ At the time this study was conducted, the Euro was not yet introduced ( 1 euro is about BEF 40).
}

board ('1' for an existing word, '3' for a non-existing word). The 30 letter strings were preceded by primes. The words used as primes (all presented in Dutch) were retained from a pre-test in which students had to indicate which words were most characteristic for a religious or business stereotype. In the religious stereotype priming condition participants were primed with priest, prayer, psalm, incense, father, missionary, religious, monk, forgiveness, brother, reverend, evangel, host, Christian, holy. In the business stereotype priming condition participants were primed with manager, firm, salesman, stocks, director, executive, businessman, trader, turnover, dynamic, company-car, business, commercial, enterprising, career. In the neutral priming condition, only words unrelated to both the religious and business stereotype (e.g., light, curved, green) were selected. Primes were presented for $17 \mathrm{~ms}$ and masked by a row of X's ("XXXXXXXXXXXX"). The mask remained on the screen for $225 \mathrm{~ms}$ and was immediately followed by the target word. In all conditions, the 15 different primes were used twice.

Measuring cooperative behavior in a dictator game. Next, participants took part in a dictator game. Each participant was told that $\mathrm{s}$ /he was paired with another person in the lab, of whom they did not receive information. Each participant was given eight chips and had to imagine that each chip was worth BEF 5. It was told that the other had not received anything. The participant could unilaterally decide about the allocation of the chips. The dictator game tested to which extent participants were willing to pass chips to the other. Participants could either keep all of the chips for themselves, or allocate any proportion to the other.

Post-experimental questionnaire. A final questionnaire indicated that none of the participants retrieved any of the primes, noticed that primes were presented, or indicated any suspicion that the tasks were related.

\section{Results}

We analyzed our data with a series of multiple regressions using SVO, consistency of SVO, and primes along with their interactions as predictors and the number of chips that participants allocated to the other as our criterion. We mean centered SVO and consistency of SVO. Also, in order to accommodate for our three prime conditions, we relied on a set of two dummy-codes that allowed us to compare religious to neutral primes (i.e., the $\mathrm{R}$-contrast) on the one hand and business to neutral primes (i.e., the B-contrast) on the other. Specifically, we allocated the values of $1,0,0$ for the R-contrast and $0,0,1$ for the B-contrast to the religious, neutral, and business conditions, respectively. Three participants were omitted from the analyses because they made their choices randomly and no SVO vector could be constructed.

Step 1 of our analysis included only the main effects and proved significant, $R^{2}=.18, F(4,161)=8.92, p<.001$. As expected, the SVO main effect was significant, $b=0.013, t(161)=4.02, p<.001$, confirming that pro-socials were more cooperative, i.e., allocated more chips to the other than pro-selfs. The R-contrast also came out significantly, $b=0.64, t(161)=2.86, p<.01$, whereas the B-contrast was not significant, $b=-0.30, t(161)=-1.32, p=.19$.

Adding the two-way interactions to the model in Step 2 significantly increased the predictive power of the model, Fchange $(5,156)=10.07, p<.001$. In line with our hypothesis, the SVO $\times$ consistency of SVO interaction was significant, $b=0.001$, $t(156)=4.18, p<.001$. Follow-up analyses conducted at \pm 1 SD around the mean consistency score confirmed that the high consistent pro-socials manifested more cooperative behavior than high consistent pro-selfs, $b=0.032, t(156)=5.09, p<.0001$. In contrast, there was no difference in cooperative behavior between low con- 
sistent pro-socials and low consistent pro-selfs, $b=0.006$, $t(156)=0.94, p>.35$.

As expected, the R-contrast $\times$ consistency of SVO interaction was significant, $b=-0.038, t(156)=-2.27, p<.03$. Follow-up analyses performed at \pm 1 SD around the mean consistency score revealed that religious primes did not elicit more cooperative behavior than neutral primes among high consistent SVO individuals, $b=-0.019, t(156)=-0.07, p>.94$. In sharp contrast, religious primes led to significantly more cooperative behavior than neutral primes among low consistent SVO individuals, $b=0.92$, $t(156)=3.16, p<.002$.

Along similar lines, the B-contrast $\times$ consistency of SVO interaction was also significant, $b=0.042, t(156)=2.39, p<.02$. Follow-up analyses performed at \pm 1 SD around the mean consistency score revealed that business primes did not elicit less cooperative behavior than neutral primes among high consistent SVO individuals, $b=0.21, t(156)=0.77, p>.44$. Quite the opposite happened among low consistent SVO individuals. Here, business primes led to significantly less cooperative behavior than neutral primes, $b=-0.81$, $t(156)=-2.63, p<.01$.

When we included both three-way interactions on Step 3, we observed no increase in the predictive power of the model, Fchange $(2,154)=0.31, p>.73$. Not surprisingly, no other effect even approached a conventional level of significance.

\section{Discussion}

These results are in line with our theorizing that individuals with a highly accessible self-concept (such as high consistent SVO individuals) are less susceptible to priming influences than are individuals with a less accessible self-concept (such as low consistent SVO individuals). Indeed, cooperative behavior of high consistent SVO individuals, whom can be considered to be "schematic" pro-social or pro-self, is mainly driven by their SVO. Low consistent SVO individuals do not possess such highly accessible chronic selfconcept and this makes them more susceptible to priming concepts. This is what we observed: low but not high consistent SVO individuals' cooperative behavior assimilated to the primed concepts.

\section{Experiment 2}

Experiment 2 aimed at providing evidence that there are circumstances where low consistent SVO individuals can resist priming influences. By activating the self-concept, low consistent individuals' chronic self-concept content may become more accessible and overcome priming influences. Research in social cognition suggests that one-way to reduce priming effects on behavior and make one's goals and dispositions more accessible is by temporarily activating the self-concept. Temporarily activating the self-concept should lead to lower susceptibility to environmental influences and activate more strongly one's one dispositions (Carver \& Scheier, 1981). Thus, activating the self for low consistent SVO individuals should weaken priming influences on their cooperative behavior.

\section{Method}

\section{Participants and design}

A group of 143 undergraduates participated in this experiment in partial fulfillment of course requirements. They were randomly assigned to one of the three priming conditions (religious vs. neutral vs. business) and one of the two self-activation conditions (high vs. low). The dependent variable was the amount of outcomes allocated to the other in a dictator game.

\section{Procedure}

A larger group of 288 undergraduate came to the lab and performed the Ring Measure of Social Values. The purpose was that only those with a lower consistency score would participate in Experiment 2. Participants with a consistency score of at most $85 \%$ were classified as low consistent SVO individuals (following Smeesters et al., 2003). The Ring Measure data of all participants were written to a separate file on a hard disk to which only the experimenter had access. The experimenter checked which participants had a consistency score of lower than 85\% (in total 143) while they were performing a filler task that took about $15 \mathrm{~min}$. These participants were then randomly assigned to one of three priming conditions and one of the two self-activation conditions.

Self-activation manipulation. Next, participants performed a translation task, which was used to increase the level of self-activation for half of the participants. Participants received 12 sentences written in Cyrillic Russian. In each sentence, one word had to be translated. In the self-activation condition, the words participants could choose for translation were first person pronouns (I, me, my, myself, mine, I myself). Earlier research demonstrated that using first person pronouns increases self-activation (Hamilton \& Shuminsky, 1990). Participants in the control condition had to translate words related to locations (city, village, place, parish, district, hamlet). The data from one participant, who reported speaking Russian, were excluded from the analysis.

Priming task and dictator game task. Following the translation task, participants were randomly assigned to one of the three priming conditions. This priming procedure was exactly the same as in Experiment. All participants then completed a similar dictator game as in Experiment 1. Participants received 10 coins of $€ 0.20$ that they had to allocate between themselves and the recipient.

Finally, a funneled debriefing procedure revealed that none of the participants indicated any suspicion regarding the priming procedure or the relatedness among tasks.

\section{Results}

We analyzed our data with a series of multiple regressions using SVO, primes, and self-activation along with their interactions as predictors and the number of chips that participants allocated to the other as our criterion. SVO was mean centered. As in Experiment 1 , we analyzed the priming effects with a set of two dummy-codes that allowed us to compare religious to neutral primes (i.e., the R-contrast) on the one hand and business to neutral primes (i.e., the B-contrast) on the other. Two participants were not included in the analysis because they made their choices on the Ring Measure randomly. Further, two other participants were omitted from the analysis because their data rendered them statistical outliers due to large studentized deleted residuals (see McClelland 2000). Hence, 138 participants were left for the analysis.

Step 1 of our analysis included only the main effects and proved significant, $R^{2}=.17, F(4,133)=6.98, p<.001$. The SVO main effect was significant, $b=0.022, t(133)=3.99, p<.0001$, indicating that pro-socials were generally more cooperative, i.e., allocated more chips to the other, than pro-selfs. Further, the B-contrast was also significant, $b=-0.82, t(133)=-2.35, p=.02$.

Adding the two-way interactions to the model in Step 2 significantly increased the predictive power of the model, Fchange(5, $128)=3.80, p<.01$. The self-activation $\times \mathrm{R}$-contrast interaction was very close to significance, $b=-0.666, t(128)=-1.97$, $p=.051$. In line with our hypotheses, follow-up analyses confirmed that religious primes led to more cooperative behavior than neutral primes among participants in the low self-activation condition, 
$b=0.99, t(128)=2.02, p<.05$, but not among participants in the high self-activation condition, $b=-0.34, t(128)=-0.73, p>.46$. In a similar vein, the self-activation $\times \mathrm{B}$-contrast interaction was marginally significant, $b=0.549, t(128)=1.62, p=.107$. Further examination of the slopes revealed that a confrontation with the business primes generated significantly less cooperation than neutral primes among participants in the low self-activation condition, $b=-1.41, t(128)=-2.93, p<.004$, whereas no difference emerged among participants in the high self-activation condition, $b=-0.31$, $t(128)=-0.67, p>.50$.

The data also revealed the presence of a significant $\mathrm{SVO} \times \mathrm{B}$ contrast interaction, $b=-0.025, t(128)=-1.98, p=.05$. Complementary analyses showed that, among pro-social participants, the business primes induced significantly less cooperation than neutral primes, $b=-1.53, t(128)=-3.17, p<.002$. No such difference emerged among pro-self participants, $b=-0.19$, $t(128)=-0.42, p>.67$.

Finally, when we included both three-way interactions on Step 3 , we observed no increase in the predictive power of the model, Fchange $(2,126)=.006, p>.60$. No other effect approached a conventional level of significance.

\section{Discussion}

Experiment 2 confirmed that the activation of the self-concept can moderate priming effects. Low consistent SVO individuals in the low self-activation condition were clearly influenced by the primes, replicating the pattern already observed in Experiment 1. In contrast, low consistent SVO individuals in the high self-activation condition were not affected by religious or business primes. Our findings suggest that making people's chronic self-concept content more accessible (by activating their self) makes them more impervious to priming effects.

\section{General discussion}

This research examined two boundary conditions of priming influences on behavior. A first, and important, boundary condition for priming effects is the chronic accessibility of behavioral responses. We predicted and found in Experiment 1 that high consistent SVO individuals were impervious to primed religious and business constructs in contrast to low consistent SVO individuals. In addition, we found that only the behavior of high consistent SVO was directed by their own SVO, whereas the behavior of low consistent SVO was directed by the primes. This suggests that primed behavioral responses only operate on behavior when one does not have relevant behavioral responses chronically accessible.

A second boundary condition is the activation of the self. In general, when the self-concept becomes more active, priming influences should diminish (Carver \& Scheier, 1981). Activating the self should particularly diminish the effects of priming influences on the behavior of individuals with a less accessible self-concept. Unlike the latter individuals, individuals with a highly accessible self-concept already have an active self. In Experiment 2, we found that primes only determined the behavior of low consistent SVO individuals when the self was not activated.

\section{Priming behavior}

Past research on behavioral priming demonstrated that the wide impact it has on behavior. It showed that norms, stereotypes, and goals can become implicitly activated and steer our social behavior. These findings have largely answered the 'first-generation' question: priming works (Bargh, 2006). Researchers now need to move on to 'second-generation' questions, such as the specific mechanisms underlying priming effects and individual differences in susceptibility to priming effects (Bargh, 2006). According to some of the proposed behavioral priming mechanisms, primed constructs can directly activate behavioral representations (Dijksterhuis \& Bargh, 2001) or activate specific components of the self-concept and as such influence behavior (Wheeler et al., 2007). Our studies, however, demonstrate that whether primes affect behavior can depend on the chronic accessibility of the self-concept or the activation of the self-concept.

Our results support the idea that chronic accessibility of the self-concept (in our case consistency of SVO) is important to consider when studying behavioral priming effects. In our studies, the consistency of a SVO predicts the extent to which individuals want to consistently enact their most dominant orientation (Hertel \& Fiedler, 1998). High consistent SVO individuals are more likely to consistently enact pro-social or pro-self behavioral tendencies, whereas low consistent SVO individuals are less likely to consistently enact such tendencies. Therefore, chronic active self-concept content should be more accessible for high consistent SVO individuals than for low consistent SVO individuals, which is reflected in a stronger influence of SVO and weaker influence of primes on high consistent SVO individuals' behavior. For low consistent SVO individuals, increased self-activation lowered the adherence to the primed constructs. This shows that, next to chronic accessibility of the self-concept, self-activation is also an important variable in studying susceptibility to priming effects.

Future studies should further test the role of the strength of the self-concept in moderating priming effects, and replicate results across other priming constructs and behavioral domains. DeMarree et al. (2007) describe strength of the self-concept as a concept that is enduring and has a great impact on behavior. They argue that the Markus' schematicity concept (Markus, 1977) can be seen as an indicator of self-strength. Thus, individuals with a highly accessibly (strong) self-concept are more likely to behave according their self-concept than individuals with a less accessible (weak) selfconcept, who are more likely to behave according situational cues. It is only when their self-concept becomes activated that the latter individuals become impervious to primes.

\section{Individual differences in susceptibility to priming influences}

Our findings add to the growing literature studying individual differences in susceptibility to priming effects. Several studies have used individual difference variables to explain mechanisms for prime-to-behavior effects. Hull, Slone, Meteyer, and Matthews (2002) found that priming effects were stronger for high self-consciousness individuals. For instance, high (but not low) self-conscious participants walked slower when primed with the elderly stereotype compared to a control condition. They argued that primed concepts only affect behavior when they are processed to be self-relevant, which should only occur for high self-conscious individuals (see also Wheeler, Morrison, DeMarree, \& Petty, 2008). Research on the Active Self account of prime-to-behavior effects found that low self-monitors were more susceptible to priming effects than high self-monitors (DeMarree, Wheeler, \& Petty, 2005). The reason is that primes activate specific self-concept content, and especially low self-monitors tend to act in line with their self-concept.

Other research found that high self-monitors can show larger priming effects than low self-monitors, under certain conditions. Because high self-monitors are susceptible to situational incentives, they may respond more to primes that have a normative component (e.g., pictures of a library) or the goals that significant others have for oneself (Morrison, Wheeler, \& Smeesters, 2007). In all these studies, however, the individual difference variables (e.g., self-consciousness, self-monitoring) were not directly related 
to the dependent variable (e.g., walking, resolving anagrams), but rather personality characteristics that reflect how individuals in general respond to individuals or social cues.

\section{Conclusion}

In two studies, we examined individuals' susceptibility to priming influences. We found evidence for two factors that can determine whether individuals' behavior is determined by priming influences or by the own self-concept: (a) the chronic accessibility of the self-concept, and (b) the momentary activation of the selfconcept. The present work on the role of the self-concept in resisting or facilitating priming influences sheds new light on the complex and dynamic nature of situation $\times$ disposition influences on social behavior.

\section{References}

Aarts, H., \& Dijksterhuis, A. (2003). The silence of the library: Environment, situational norm, and social behavior. Journal of Personality and Social Psychology, 84, 18-28.

Bargh, J. A. (2006). What have we been priming all those years? On the development, mechanisms, and ecology of nonconscious social behavior. European Journal of Social Psychology, 36, 147-168.

Bargh, J. A., Chen, M., \& Burrows, L. (1996). Automaticity of social behavior: Direct effects of trait construct and stereotype activation on action. Journal of Personality and Social Psychology, 71, 230-244.

Bargh, J. A., \& Ferguson, M. J. (2000). Beyond behaviorism: On the automaticity of higher mental processes. Psychological Bulletin, 126, 925-945.

Bohnet, I., \& Frey, B. S. (1999). The sound of silence in prisoner's dilemma and dictator games. Journal of Economic Behavior and Organization, 38, 43-57.

Carver, C. S., \& Scheier, M. F. (1981). Attention and self-regulation: A control-theory approach to human behavior. New York: Springer.

De Dreu, C. K. W., Yzerbyt, V. Y., \& Leyens, J.-P. (1995). Dilution of stereotype-based cooperation in mixed-motive interdependence. Journal of Experimental Social Psychology, 31, 575-593.

DeMarree, K. G., Petty, R., \& Brinol, P. (2007). Self and attitude strength parallels: Focus on accessibility. Social and Personality Psychology Compass, 1, 441-468.

DeMarree, K. G., Wheeler, S. C., \& Petty, R. E. (2005). Priming a new identity: Selfmonitoring moderates the effects of nonself primes on self-judgments and behavior. Journal of Personality and Social Psychology, 89, 657-671.

Dijksterhuis, A., \& Bargh, J. A. (2001). The perception-behavior expressway: Automatic effects of social perception on social behavior. In M. Zanna (Ed.). Advances in Experimental Social Psychology (Vol. 33, pp. 1-40). Hillsdale, NJ: Lawrence Erlbaum Associates.

Dijksterhuis, A., Chartrand, T. L., \& Aarts, H. (2007). Effects of priming and perception on social behavior and goal pursuit. In J. A. Bargh (Ed.), Social psychology and the unconscious: The automaticity of higher mental processes (pp. 51-132). New York, NY: Psychology Press.

Dijksterhuis, A., \& Van Knippenberg, A. (2000). Behavioral indecision: Effects of selffocus on automatic behavior. Social Cognition, 18, 55-74.

Epley, N., \& Gilovich, T. (1999). Just going along: Nonconscious priming and conformity to social pressure. Journal of Experimental Social Psychology, 35, $578-589$.

Epstein, S. (1983). Aggregation and beyond: Some basic issues on the prediction of behavior. Journal of Personality, 51, 360-392.
Hamilton, J. C., \& Shuminsky, T. R. (1990). Self-awareness mediates the relationship between serial position and item reliability. Journal of Personality and Social Psychology, 59, 1301-1307.

Hertel, G., \& Fiedler, K. (1994). Affective and cognitive influences in a social dilemma game. European Journal of Social Psychology, 24, 131-145.

Hertel, G., \& Fiedler, K. (1998). Fair and dependent versus egoistic and free: Effects of semantic and evaluative priming on the 'Ring Measure of Social Values'. European Journal of Social Psychology, 28, 49-70.

Hull, J. G., Slone, L. B., Meteyer, K. B., \& Matthews, A. R. (2002). The nonconsciousness of self-consciousness. Journal of Personality and Social Psychology, 83, 406-424.

Kay, A. C., \& Ross, L. (2003). The perceptual push: The interplay of implicit cues and explicit situational construals on behavioral intentions in the Prisoner's Dilemma. Journal of Experimental Social Psychology, 39, 634-643.

Liebrand, W. B. G. (1984). The effect of social motives, communication and group size on behavior in an N-person multi-stage, mixed-motive game. European Journal of Social Psychology, 14, 239-246.

Markus, H. R. (1977). Self-schemata and processing information about the self. Journal of Personality and Social Psychology, 35, 63-78.

McClintock, C. G. (1972). Social motivation-A set of propositions. Behavioral Science, $17,438-454$.

McClelland, G. H. (2000). Nasty data: Unruly, ill-mannered observations can ruin your analysis. In H. T. Reis \& C. M. Judd (Eds.), Handbook of research methods in social and personality psychology. New York: Cambridge University Press.

Messick, D. M., \& McClintock, C. G. (1968). Motivational bases of choice in experimental games. Journal of Experimental Social Psychology, 4, 1-25.

Morrison, K. R., Wheeler, S. C., \& Smeesters, D. (2007). Significant other primes and behavior: Motivation to respond to social cues moderates pursuit of primeinduced goals. Personality and Social Psychology Bulletin, 12, 1661-1674.

Nelson, L. D., \& Norton, M. I. (2005). From student to superhero: Situational primes shape future helping. Journal of Experimental Social Psychology, 41, 423-430.

Neuberg, S. L. (1988). Behavioral implications of information presented outside of conscious awareness: The effect of subliminal presentation of trait information on behavior in the prisoner's dilemma game. Social Cognition, 6, 207-230.

Sattler, D. N., \& Kerr, N. L. (1991). Might versus morality explored: Motivational and cognitive bases for social motives. Journal of Personality and Social Psychology, 60, 756-765.

Smeesters, D., Warlop, L., Van Avermaet, E., Corneille, O., \& Yzerbyt, V. (2003). Do not prime hawks with doves: The interplay of consistency of social value orientation and construct activation on cooperative behavior. Journal of Personality and Social Psychology, 84, 972-987.

Smeesters, D., Wheeler, S. C., \& Kay, A. C. (in press). The role of interpersonal perceptions in the prime-to-behavior pathway. Journal of Personality and Social Psychology.

Utz, S. (2004). Self-activation is a two-edged sword: The effects of I primes on cooperation. Journal of Experimental Social Psychology, 40, 769-776.

Utz, S., Ouwerkerk, J. W., \& Van Lange, P. A. M. (2004). What is smart in a social dilemma? Differential effects of priming competition on cooperation. European Journal of Social Psychology, 34, 317-332.

Van Lange, P. A. M. (1999). The pursuit of joint outcomes and equality in outcomes: An integrative model of social value orientation. Journal of Personality and Social Psychology, 77, 337-349.

Van Lange, P. A. M., \& Liebrand, W. B. G. (1989). On perceiving morality and potency: Social values and the effects of person perception in a give-some dilemma. European Journal of Personality, 3, 209-225.

Wheeler, S. C., DeMarree, K. G., \& Petty, R. E. (2007). Understanding the role of the self in prime-to-behavior effects: The active-self account. Personality and Social Psychology Review, 11, 234-261.

Wheeler, S. C., Morrison, K. R., DeMarree, K. G., \& Petty, R. E. (2008). Does selfconsciousness increase or decrease priming effects? It depends. Journal of Experimental Social Psychology, 44, 882-889.

Wheeler, S. C., \& Petty, R. E. (2001). The effects of stereotype activation on behavior: A review of possible mechanisms. Psychological Bulletin, 127, 797-826. 